\title{
La planeación y el presupuesto como sistemas simbólicos articulados a los procesos de resistencia campesina: análisis de una organización a partir de los referentes teóricos de Pierre Bourdieu ${ }^{1}$
}

Recibido: 13 de mayo de 2012

Aprobado: 17 de junio de 2012

Juan David Cardona Hernández ${ }^{2}$

Yuliana Hinestroza Rojas ${ }^{3}$

Cardona, H. e Hinestroza, Y. (2013). La planeación y el presupuesto como sistemas simbólicos articulados a los procesos de resistencia campesina: análisis de una organización a partir de los referentes teóricos de Pierre Bourdieu. Activos, 20, 55-101.

\section{Clasificación JEL: E01}

\section{Resumen}

En aras de ampliar los marcos para el entendimiento del rol que desempeña la contabilidad en las organizaciones, se propone, a partir de los elementos conceptuales del teórico francés Pierre Bourdieu, analizar la situación de una organización de resistencia campesina, identificando la articulación

1 Artículo producto de la investigación realizada como parte del trabajo de grado para optar al título de Contador Público en la Universidad de Antioquia.

2 Contador Público de la Universidad de Antioquia. Docente Investigador Facultad de Ciencias Empresariales, Corporación Universitaria Remington. Correo electrónico: jdcardonah@yahoo.es

3 Contadora Pública de la Universidad de Antioquia. Correo electrónico: yuliana00528@gmail.com 
de la planeación y el presupuesto con el proceso social que se gesta desde la comunidad, buscando evidenciar la forma en que la disciplina opera en un contexto con lógicas cualitativamente divergentes a las predominantes en el ámbito organizacional de la empresa privada. De esto, se entienden la planeación y el presupuesto como sistemas simbólicos donde se inscriben lógicas que permiten la cognición y la comunicación, en un proceso en el cual se imbrican las relaciones de poder. Producto de unas formas particulares de relacionamiento, la contabilidad es entendida como un conocimiento en el cual la realidad es recreada y construida, lo cual se inscribe en el marco de unas relaciones de poder específicas que trascienden y penetran en la construcción de lo social, más allá de los marcos netamente económicos y financieros.

Cardona, H. e Hinestroza, Y. (2013). Planning and budgeting as symbolic systems articulated to peasant resistance processes: Analysis of an organization from Pierre Bourdieu's theoretical framework. Activos, 20, 55-101.

\section{Palabras clave}

Contabilidad, planeación y presupuesto, sistema simbólico, Pierre Bourdieu, organizaciones campesinas

\section{Abstract}

In order to expand the framework for understanding the role played by accounting in organizations, an analysis from the conceptual elements of the French theorist Pierre Bourdieu, analyzing the situation of an organization of peasant resistance is proposed, identifying articulation of planning and budgeting with the social process set up by the community, seeking to demonstrate how the discipline operates in a context with qualitatively divergent logics from those prevailing in the organizational environment of private enterprise. From this, the planning and budgeting are understood as a symbolic system where there are logics that allow cognition and communication, in a process in which power relationships overlap. 
Product of a particular form of relationship, accounting is understood as a knowledge in which reality is recreated and built, by a community. It falls under the framework of specific relationships of power that transcend it and penetrate the social construction, beyond the purely economic and financial frameworks.

\section{Keywords}

Contabilidad, planeación y presupuesto, sistema simbólico, Pierre Bourdieu, organizaciones campesinas

Cardona, H. e Hinestroza, Y. (2013). La planification et le budget comme systèmes symboliques articulés aux processus de résistance des paysans: analyse d'une organisation à partir des référents théoriques de Pierre Bourdieu. Activos, 20, 55-101.

\section{Résumé}

Afin délargir les cadres pour mieux comprendre le rôle joué par la comptabilité dans les organisations, on propose une analyse fondée sur les éléments conceptuels du théoricien Français Pierre Bourdieu. On compte faire ceci en analysant la situation d'une organisation de résistance des paysans, en identifiant l'articulation de la planification et le budget avec le processus social conçu depuis la communauté et en cherchant la mise en évidence de la façon dont la discipline fonctionne dans un contexte avec des logiques qualitativement différentes à celles prédominantes dans la sphère organisationnelle de l'entreprise privée. Cela signifie que la planification et le budget sont vus comme un système symbolique où il $\mathrm{y}$ a des logiques qui permettent la cognition et la communication, dans un processus dont les relations de pouvoir sont imbriquées. Produit des formes particulières de relation, la comptabilité est comprise comme une connaissance spécifique dans laquelle la réalité est recréée et construite, ce qui s'inscrit dans le cadre des relations de pouvoir spécifiques qui transcendent et pénètrent dans la construction sociale, au-delà des cadres purement économiques et financiers. 


\section{Mots clés:}

Comptabilité, planification et budget, système symbolique, Pierre Bourdieu, organisations paysannes

Aqui las heridas sociales se profundizan en el tiempo y en los distintos escenarios sociales. No obstante, como las insumisas flores que brotan en medio del cemento, las luchas y las resistencias sociales surgen, renacen y persisten en y en contra de la misma muerte. Un caso emblemático de esta lógica social es el Oriente Antioqueño.

Pérez, L. (2011)

\section{Introducción}

En una época donde la competencia y la lógica de la acumulación y la ganancia imperan, donde las crisis económicas se hacen más recurrentes a costa de la miseria de millones en el mundo, se hace necesario que los pocos que se resisten a aceptar que esta sociedad sea la mejor posible, faciliten y hagan parte de la construcción de espacios en los cuales se vincule la reflexión crítica y fundamentada, con prácticas concretas, que incidan en la transformación de los diferentes ámbitos donde transcurre su existir.

Pareciese que dicho imperativo le incumbiera únicamente a las ciencias sociales, y no a una disciplina "objetiva y neutral" como la contabilidad. Pese a estas posiciones, en el campo contable se han empezado a abrir paso posturas heterodoxas que deslindan con aquel pensar y sentir acrítico sumido bajo la racionalidad instrumental del capital, posicionando a la contabilidad como un saber social, permitiendo, desde una mirada más amplia, comprender las incidencias de lo contable en la construcción de la realidad. 
En esta dirección, y asumiendo un compromiso ante los grandes dilemas por los cuales atraviesa la humanidad, se hace necesario empezar a develar, desde la investigación, los caminos por los cuales, a partir de lo disciplinar, se pueda comprender la realidad, y en ese sentido, aportar para transformarla.

De esta forma, la presente investigación pretende dar referentes de análisis a partir de diversos elementos conceptuales del sociólogo francés Pierre Bourdieu para el entendimiento de la manera en que la contabilidad, a través de la planeación y el presupuesto, se articula a la realidad organizacional, explorando la forma particular en que dicha articulación es posible y sus implicaciones. Además, se procura aplicar esa lectura al caso de una organización, en un proyecto de resistencia social como el que se gesta en la Asociación de Pequeños y Medianos Productores del Oriente Antioqueño (ASOPROA), con lógicas totalmente divergentes a los ámbitos a los cuales, por lo general, se articula lo contable.

Para dicho cometido, la investigación se fundamenta en los parámetros de la investigación social cualitativa, más específicamente en un trabajo de campo en el que confluyen la observación participante, la revisión documental y las entrevistas semiestructuradas, entendiendo así los referentes sociales, políticos y éticos que implica dicho tipo de investigación (Galeano, 2004).

En concordancia, el presente artículo se desarrollará en cinco acápites. En el primer capítulo se abordarán inicialmente los elementos conceptuales de la investigación, enfatizando en los preceptos teóricos del sociólogo francés Pierre Bourdieu, lo cual permitirá tener bases para un entendimiento relacional de la asociación y la contabilidad en sus aspectos presupuestales y de planeación. En el segundo acápite se disertará sobre la contabilidad que, como sistema simbólico, es producto de una construcción social, lo cual, siguiendo a Bourdieu, se configura en un arbitrario histórico y cultural, presentando diversos componentes conceptuales que permitirán entender la articulación de la planeación y el presupuesto en la organización en cuestión. Con esto, el tercer capítulo analiza, a partir de los referentes teóricos, cómo 
ASOPROA busca incidir en la realidad y transformación de su región. El siguiente apartado pretende, a partir de la información obtenida por medio de los instrumentos de investigación y los elementos conceptuales previamente presentados, entender la forma en que la planeación y el presupuesto se articulan a ASOPROA. Por último, se presentarán algunas conclusiones.

\section{Elementos teóricos y conceptuales de la teoría de Bourdieu}

La importancia del constructo teórico de Pierre Bourdieu reside en que permite, de una manera dialéctica, vincular la práctica social con los elementos estructurales y de poder construidos social e históricamente. Bourdieu y Wacquant plantean en congruencia: "sin duda la sociedad tiene una estructura objetiva, pero no es menos cierto que también se compone, de modo decisivo, de 'representación y voluntad"' (Bourdieu y Wacquant, 1992, p. 34). Es así como "el individuo no es amo de su destino, en el sentido de ser un sujeto libre y transparente, ni es una simple marioneta de las estructuras sociales" (Téllez, 2002, p. 45).

A lo anterior se suma la posibilidad de entender de manera diacrónica la realidad, vinculando los diferentes elementos del tiempo en la producción, reproducción y cambio social, es decir, el pasado como parte de la realidad colectiva e individual, que conjugado con los proyectos de futuro (implícitos o explícitos), hace que las prácticas presentes, jerarquías, formas de relacionarse, de pensar y entender el mundo de los agentes e instituciones estén cargadas de todo un proceso colmado de historia y sentido.

Otro aspecto importante de la teoría de Bourdieu está en que lo relacional es parte fundamental de su constructo teórico, es decir, como lo argumentan Bourdieu y Wacquant (1992): "contra todas las formas del monismo metodológico que conlleva aseverar la prioridad ontológica de la estructura o el agente, del sistema o el actor, de lo colectivo o lo individual, Bourdieu afirma la primacía de las relaciones" (p. 42). Así, los hechos sociales son vistos como un conjunto de relaciones entre los agentes, y de estos con las estructuras e instituciones. Esto se debe a que esta manera de entender la 
realidad es más adecuada para expresar relaciones que cosas, y procesos, más que estados (Bourdieu y Wacquant, 1992, p. 42).

Desde esta óptica, los conceptos de Espacio social, Campo, Capital, Habitus, Illusio y Estrategias pasan a desempeñar un papel fundamental en el entendimiento del devenir social e individual, lo cual permite articular lo estructural, las relaciones de poder, los campos, las posiciones en el espacio social y en los campos con las formas de apropiación del trabajo material o inmaterial, los agentes y sus luchas cotidianas e históricas.

\subsection{Espacio social y Campos}

Para Bourdieu, el mundo social puede ser representado en forma de espacio pluridimensional, construido sobre la base de principios de diferenciación o distribución en el que los agentes ocupan posiciones disímiles y se relacionan a partir del poder actuante (tipos de capital) que posean. En este sentido, señala Bourdieu: los agentes se distribuyen en el espacio social, "en una primera dimensión, según el volumen global de capital que poseen y, en una segunda, según la composición de su capital, es decir, según el peso relativo de las diferentes especies en el conjunto de sus posesiones" 4 (1997, p. 18).

El Espacio social es descrito como un campo de fuerzas en el que los vínculos que se (re)construyen continuamente afectan a todos aquellos adscritos al conjunto de relaciones que allí se gestan. Los agentes están entonces dotados de especies diferentes y desiguales de capital, lo que

4 En particular, Bourdieu le da una importancia significativa al capital económico y al cultural en la definición de la posición de los agentes en el espacio social. Si bien esto se define para "las sociedades más avanzadas" (Bourdieu, 1997, p. 18), sería posible considerar igualmente significativo el papel de dichos capitales en nuestros contextos, lo que no aplicaría para todo el conjunto de microcosmos o campos de manera análoga, pues, como se verá más adelante, cada campo tiene sus singularidades, por lo cual los tipos de capital tienen efectos diversos y "pesos" relativos según el caso (Bourdieu, 1997, pp. 11-31). 
hace que se definan relaciones de proximidad o distanciamiento según la cantidad y composición del capital que se posea.

Dicho espacio, con su diferenciación y divisiones, es algo que los agentes construyen individual y colectivamente, en cooperación y en conflicto, a partir de la posición ocupada en la estructura del espacio social, lo cual genera un tipo particular de representación del mundo y de toma de posición en las luchas por conservar o transformar los diversos escenarios de existencia (Bourdieu, 1997).

El Espacio social está conformado por diversos microcosmos que Bourdieu denomina con el concepto de campos. Estos son "microcosmos sociales relativamente autónomos, es decir, espacios de relaciones objetivas que son el sitio de una lógica y una necesidad específicas e irreductibles a aquellas que regulan otros campos" (Bourdieu y Wacquant, 1992, p. 135).

En congruencia, cada campo se caracteriza por un conjunto de jerarquías y relaciones de poder singulares que abarcan desde las formas en que las personas se distribuyen los recursos, a las prácticas particulares que se derivan de ese conjunto específico de relaciones y procesos con sus propios principios reguladores y valores (Bourdieu y Wacquant, 1992). Un campo, más que un sector delimitado dentro de la realidad social, es un conjunto específico de relaciones diferenciadas y diferenciadoras. En estos términos, Bourdieu y Wacquant (1992) definen campo como:

Una red o una configuración de relaciones objetivas entre posiciones. Estas posiciones están objetivamente definidas, en su existencia y en las determinaciones que imponen sobre sus ocupantes, agentes o instituciones, por su situación presente y potencial (situs) en la estructura de distribución de especies del poder (o capital) cuya posesión ordena el acceso a ventajas específicas que están en juego en el campo, así como por su relación objetiva con otras posiciones (dominación, subordinación, homología, etcétera) (p. 150). 
Esta configuración particular de relaciones vincula, de manera dialéctica, la unidad y la lucha, es decir, en cada campo hay unos intereses fundamentales comunes, que vinculan a los agentes a la existencia del campo, lo que hace que surjan complicidades subyacentes (Bourdieu, 1990); esa unidad y complicidad están caracterizadas por la lucha (no necesariamente antagónica) que existe a partir de las posiciones de los agentes, los tipos de capitales e intereses que estos poseen, lo recursos materiales o inmateriales que están en juego al interior del campo (Bourdieu, 2002b). Es entonces por medio de esta unidad y lucha en la que se juega en cada momento la permanencia, el cambio o la transformación de las fronteras, las formas y la existencia del mismo campo (Bourdieu y Wacquant, 1992).

\subsection{Capital}

El concepto de capital para Bourdieu debe ser entendido como "trabajo acumulado, bien en forma interiorizada o incorporada” (2000a, p. 131), lo que posibilita entender los intereses y las formas de poder en ámbitos distintos al económico, ya que las relaciones y los tipos de intercambios sociales van más allá de dicho ámbito, pues desde allí únicamente se reconoce el interés y las prácticas sociales de manera reduccionista, entendidas exclusivamente en términos de la racionalidad derivada de la maximización del beneficio económico; "en efecto, es imposible dar cumplida cuenta de la estructura y funcionamiento del mundo social a no ser que reintroduzcamos el concepto de capital en todas sus manifestaciones, y no solo en la forma reconocida por la teoría económica" (Bourdieu, 2000a, p. 133). En consonancia, las diferentes especies de capital son susceptibles de acumulación, en torno a la cual puede constituirse un proceso de producción, distribución y consumo y, por tanto, un mercado (Padilla, 2007).

Además, para que un capital tenga incidencia en un campo, es necesario que éste sea eficaz, que los agentes puedan disponer de él en el acontecer del campo, de tal forma que le confiera al portador poder. 
Esto es así porque, en el fondo, el valor de una especie de capital (por ejemplo, el conocimiento del griego o del cálculo integral) depende de la existencia de un juego, de un campo donde tal competencia pueda ser utilizada: una especie de capital es aquello que es eficaz en un campo determinado, tanto a modo de arma como de asunto en juego en la contienda, que permite a sus poseedores disponer de un poder, una influencia, y por tanto existir en el campo en consideración, en lugar de ser considerado una cifra desdeñable (Bourdieu y Wacquant, 1992, p. 152).

En este sentido, Bourdieu habla de capital económico, cultural, social; y del capital simbólico como forma singular de capital ${ }^{5}$.

Capital económico: son los bienes de naturaleza económica (asociados al poder adquisitivo), entre los cuales el dinero, por su función de equivalente universal de todas las mercancías, ocupa un lugar preponderante (Téllez, 2002).

Capital cultural: el capital cultural puede existir en tres formas o estados: en estado interiorizado o incorporado, esto es, en forma de disposiciones duraderas del organismo; en estado objetivado, en forma de bienes culturales, cuadros, libros, diccionarios, instrumentos o máquinas, que son el resultado y muestra de la disputas intelectuales, de teorías y de sus críticas; $\mathrm{y}$, finalmente, en estado institucionalizado, una forma de objetivación que debe considerarse aparte porque, como veremos en el caso de los títulos académicos, confiere propiedades enteramente originales al capital cultural que debe garantizar (Bourdieu, 2000a, p. 136).

Capital social: está constituido por la totalidad de los recursos potenciales o actuales asociados a la posesión de una red duradera de relaciones

5 Respecto a los tipos de capital, es importante señalar que estos no se restringen a los presentados en el artículo, los cuales son tomados por su relevancia respecto a la investigación; en este sentido, es relevante anotar que los tipos de capitales pueden variar según el campo estudiado. Para ver ejemplos de otros tipos de capitales se remite al lector al texto: "Espíritus de Estado, génesis y estructura del campo burocrático” (Bourdieu, 1996). 
más o menos institucionalizadas de conocimiento y reconocimiento mutuos. Expresado de otra forma, se trata aquí de la totalidad de recursos basados en la pertenencia a un grupo (Bourdieu, 2000a, p. 148).

Capital simbólico: es cualquier propiedad (cualquier especie de capital: físico, económico, cultural, social), mientras sea percibido por los agentes sociales cuyas categorías de percepción son tales que están en condiciones de conocerlo (de percibirlo) y de reconocerlo, de darle valor (Bourdieu, 1996, p. 15) .

En otras palabras, los diferentes tipos de capitales, al convertirse en capital simbólico para quien los posee (una organización, un individuo o un grupo de individuos), le significan prestigio, reputación, renombre, autoridad, etc., lo cual puede ser utilizado en su provecho, en tanto los demás lo vean como legítimo.

El capital, entonces, incide de manera diversa en el devenir de los campos y los agentes. Es importante resaltar que "los campos están definidos por las diferentes formas de capital que están en juego" (Oakes, Townley \& Cooper, 2009, p. 180), es decir, cada campo tiene sus tipos particulares de capital, de los cuales se derivan formas singulares y diferenciadas de vínculos y luchas; e interconectado con esto, según las preponderancias de los diferentes tipos de capital en el campo, se definen las jerarquías y formas de distribución de los capitales (Bourdieu y Wacquant, 1992).

En consecuencia, según el capital que posean los agentes (u organizaciones), se estructuran las posiciones dentro del campo, las formas de distribución en los mismos y las relaciones de poder. En este sentido, Bourdieu (1990) considera que:

6 De manera ilustrativa, Bourdieu plantea: el honor de las sociedades mediterráneas es una forma típica de capital simbólico que solo existe a través de la reputación, es decir, la representación que los otros se hacen en la medida en que comparten un conjunto de creencias apropiadas para hacerles percibir y apreciar ciertas propiedades y ciertas conductas como honorables o deshonrosas (Bourdieu, 1996, p. 16). 
Las especies de capital, como una buena carta en un juego, son poderes que definen las probabilidades de obtener un beneficio en un campo determinado (de hecho, a cada campo o subcampo le corresponde una especie particular de capital, vigente como poder y como lo que está en juego en ese campo) (p. 206).

\subsection{Habitus, Illusio y Estrategias}

Otro elemento transversal en la teoría de Bourdieu es el concepto de Habitus, que vinculado a los de Estrategias e Illusio, permiten tener un entendimiento mucho más complejo y rico de las prácticas de los agentes, develando así los diferentes constreñimientos a los que se enfrentan, sin condenarlos por esto a un destino sin salida alguna. El Habitus permite articular, de manera coherente, lo estructural con las prácticas de los agentes, lo social con lo individual, lo objetivo con lo subjetivo y el pasado con el presente y el futuro. Hablar de habitus es aseverar que lo individual, e incluso lo personal, lo subjetivo, es social, colectivo. El habitus es una subjetividad socializada (Bourdieu y Wacquant, 1992, p. 186). Este concepto permite articular, a su vez, los elementos particulares del campo, como son las posiciones en el espacio, los tipos de capital y las formas de poder, con las prácticas de los agentes, individuales o colectivas, abriendo así un espectro restringido, pero ilimitado, para las iniciativas, inventivas y la construcción de la realidad.

Los habitus se construyen a partir de las condiciones históricas y sociales que los agentes o una clase de agentes incorporan a partir de su posición diferenciada en el espacio social y en cada campo. Respecto a esto, Bourdieu (2007) plantea:

Los condicionamientos asociados a una clase particular de condiciones de existencia producen 'habitus', sistemas de disposiciones duraderas y transferibles, estructuras estructuradas predispuestas para funcionar como estructuras estructurantes, es decir, como principios generadores y organizadores de prácticas y representaciones que pueden estar objetivamente adaptadas a su fin, sin suponer la búsqueda consciente de fines y el dominio 
expreso de las operaciones necesarias para alcanzarlos, objetivamente "reguladas" y "regulares", sin ser el producto de la obediencia a reglas, y, a la vez que todo esto, colectivamente orquestadas sin ser producto de la acción organizadora de un director de orquesta (p. 86).

Tomando estos elementos, es necesario insistir en la forma en que opera el habitus como sistema de disposiciones. Son estructuras estructuradas, es decir, conjunto de elementos que, desde los diferentes ámbitos de la existencia individual o colectiva fueron impartidos (transmitidos implícita o explícitamente), ya sea por la familia, la escuela u otras instituciones, y que actúan como estructuras estructurantes, como juicios, valores, sistemas de valoración y percepción con los cuales se entiende y da sentido a la realidad y a los que se recurre al orientar las prácticas. El habitus, en este sentido, está en una construcción permanente, no es algo acabado y que existe de manera inmutable; por tal motivo, el habitus no es un conjunto de disposiciones que hayan sido incorporadas de manera definitiva para ser sistemáticamente aplicadas de manera homogénea (mecánica) en todas las circunstancias y contextos.

Bourdieu reconoce dos tipos de habitus íntimamente ligados, uno asociado directamente a los individuos, y otro vinculado a las colectividades, concebido como habitus de clase o grupo. Si bien cada agente en su existencia, a partir de sus singularidades y vivencias propias, es un ser único, es necesario tener presentes las formas comunes, provenientes de contextos, experiencias y prácticas derivadas de la posición en el campo o en el espacio social que los agentes comparten. Como lo mencionan Powell y DiMaggio (1999):

Debido a las historias comunes, los miembros de cada "fracción de clase" comparten un habitus similar y crean regularidades en el pensamiento, las aspiraciones, las disposiciones, los patrones de apreciación y las estrategias de acción vinculadas a las posiciones que ocupan las personas en las estructuras sociales que reproducen continuamente (p. 65). 
Esto explica entonces cómo, a partir de las singularidades de los agentes, haya prácticas comunes, formas de entender y responder de manera similar a las diversas situaciones que se presentan en la cotidianidad.

Por su parte, el concepto de Illusio se refiere al interés específico que se define en el marco de los campos y sus luchas. Este concepto deslinda con la acepción económica de interés, que lo enmarca simplemente en las lógicas del beneficio financiero. Contrario al interés en este sentido, el concepto de Illusio reconoce que si bien hay prácticas que desde lo económico aparecen como irracionales o carentes de sentido, en los límites de ciertos campos pueden tener relevancia y significado.

La Illusio es el reconocimiento, por parte de los agentes, de lo que está en juego en el campo, y de que lo que allí se disputa es importante (Bourdieu, 1997), y difiere según la posición que los agentes ocupen en el campo. Como lo plantean Bourdieu y Wacquant (1992):

La illusio es el opuesto mismo de ataraxia: es estar concernido, tomado por el juego. Estar interesado es aceptar que lo que ocurre en un juego social dado importa, que la cuestión que se disputa en él es importante (otra palabra con la misma raíz que interés) y que vale la pena luchar por ella (p. 174).

En cuanto a las diversas formas de reproducción y las tensiones al interior de los campos, Bourdieu introduce el concepto de Estrategias para designar al conjunto de acciones ordenadas en busca de objetivos, a más o menos largo plazo, que son producidos por los miembros de un colectivo (Bourdieu, 2002a). En este sentido, las estrategias son construidas por los agentes u organizaciones según su capital disponible (en sus diferentes especies), el lugar ocupado en la distribución del capital específico y de la percepción que se tenga del campo según el punto de vista que adopten sobre el campo como una visión desde un punto en el campo (Bourdieu y Wacquant, 1992; Bourdieu, 2002b). 
De lo anterior se entiende que las estrategias sean disímiles, pues la Illusio que los convoca es también diversa. Por tanto, los agentes pueden buscar de diversas formas, utilizando variados instrumentos y métodos: aumentar, conservar su capital o transformar total o parcialmente las formas de relacionamiento dentro del campo, lo cual no siempre tiene el efecto esperado, dado que el sentido del juego a partir del cual se articulan las estrategias no es infalible y está desigualmente repartido (Bourdieu, 2000b).

\section{La contabilidad como sistema simbólico y arbitrario cultural}

Bourdieu postula que el universo social tiene la particularidad de que sus estructuras llevan una "doble vida". Existen tanto en la "objetividad de primer orden", constituida por la distribución de recursos materiales y medios de apropiación de bienes y valores socialmente escasos (especies de capital, en el lenguaje técnico de Bourdieu), como también en la "objetividad de segundo orden", bajo la forma de sistemas de clasificación, esquemas mentales y corporales que funcionan a manera de patrones simbólicos para las actividades prácticas -conducta, pensamientos, sentimientos y juicios- de los agentes sociales (Bourdieu y Wacquant, 1992). Estas dos objetividades están íntimamente ligadas, y operan de manera dialéctica.

Esta perspectiva implica un marco heterogéneo de entendimiento de cómo se construye socialmente la contabilidad y su incidencia en las organizaciones y la sociedad. Todo esto desde un sentido amplio de la contabilidad, el cual abarca, entre otras, la contabilidad financiero patrimonialista, la contabilidad de gestión, y desde luego el proceso de planeación y presupuesto, además de comprender sus repercusiones en las organizaciones más allá de lo económico-financiero.

Es necesario reafirmar con Carmona (1992, citado en Gómez, 2004, p. 125), que la contabilidad, como conjunto de prácticas y herramientas sociales, debe ser abordada desde un sentir menos técnico y más sociológico y organizacional. Bajo estos parámetros, sería pertinente tomar a lo contable 
desde lo social, psicológico, político, histórico y cultural, lo cual implica, a su vez, la búsqueda de sus referentes morales, de poder y de significado (Roberts y Scapens, 2009).

En este sentido, la contabilidad puede ser entendida siguiendo a Alawattage (2011) como una Estructura Estructurada y una Estructura Estructurante. Es estructurada, en relación a 1) la condición del espacio social, del campo, subcampo (con sus habitus, preponderancias de capital, illusio, disputas y estrategias en juego) y a la estructura organizacional en un momento determinado; 2) la red específica de vínculos, tensiones y configuración de poderes (tanto en lo simbólico como en lo material) al interior del campo (o subcampo) y de éste con otros campos (por ejemplo con el campo burocrático o Estado). Lo cual a su vez incide en la forma en que los agentes entienden la organización, en la actuación práctica y en la manera en que se distribuyen los diversos tipos de capital, siendo así entonces una estructura estructurante.

Por tanto, es de entender que la contabilidad, como todo conocimiento, es una construcción social ${ }^{7}$; por ende, su análisis no puede ser abstraído de los parámetros sociales a los cuales se debe ${ }^{8}$, es decir, de las jerarquías y relaciones de poder, del habitus, los capitales, la illusio, las estrategias en juego y disputas al interior de los campos, subcampos y organizaciones.

7 De esta forma, siguiendo a Gil (2009), es pertinente resaltar que: "Es obvio que todos los saberes son sociales en cuanto pertenecen y se revierten en el conjunto de la humanidad; lo que estamos planteando no es esa generalidad, sino decir que el objeto de la contabilidad es social: pertenece, se desarrolla y se imbrica en un contexto de interacciones de hombres con hombres; si no hay contexto social, no hay contabilidad" (p. 106).

8 En esa misma dirección, afirma Mattessich,"eliminar consideraciones históricas, metodológicas, morales del estudio de la contabilidad no difiere de separar las raíces de una planta"(1995, citado en Larrinaga, 1999, p. 104). De manera análoga, plantea Larrinaga, no se puede estudiar "la contabilidad como una actividad de servicio técnica y racional que está separada de relaciones sociales más amplias. Por el contrario, ha de estudiarse como una particular forma de racionalidad calculativa que construye y a su vez es construida por relaciones sociales"(1999, p. 118). 
De ahí que, siguiendo a Bourdieu, se pueda hablar de la contabilidad como un arbitrario histórico y cultural, es decir, como un producto netamente social y cultural, que ha tomado diferentes formas y ha respondido de manera singular, en diversas culturas y épocas de la historia, a los requerimientos heterogéneos de información y control (Vlaemminck, 1991). Es decir, la estructura y las funciones de la contabilidad y los intereses que agencia son una construcción social (una de las tantas posibles), que al igual que han sido construidas socialmente, pueden ser transformadas desde lo colectivo.

En consecuencia, plantea Tovillas (2010), las taxonomías clasificatorias y las formas en que los individuos o grupos entienden el mundo y que los agentes portan, presentadas como de carácter "natural" y consideradas como inmutables, resultan ser el producto de una imposición arbitraria, un arbitrario cultural. Así lo plantea Gil (2003):

La contabilidad es uno de los ojos de nuestra cultura, y cada civilización y cada cultura determinan la manera en que el hombre observa la realidad. Hay elementos que nos condicionan a enfocar solo ciertas regiones de la realidad. Las estructuras decisionales son una variable cultural e histórica (...) Por eso, los problemas no son relevantes por sí mismos, es la sociedad la que les da prioridad y ordena su importancia (p. 27).

Ese carácter interesado de la contabilidad lleva a Mattessich a definirla como pragmática, puesto que -plantea este autor- opera de manera similar a pintar un cuadro, o hacer un retrato con un propósito específico, a partir de cierta perspectiva y de ciertos lineamientos e intereses (2003, p. 20). Y en esa misma dirección Gómez (2007) señala que es una disciplina "teleológica" porque busca conseguir objetivos o satisfacer necesidades. Esto es, los objetivos de los usuarios (p. 250).

Por otra parte, la contabilidad, al ser una estructura estructurante y al hacer parte de la realidad de segundo orden, se presenta como un Sistema Simbólico, a partir del cual se entiende ("conoce"), comunica, proyecta y se da sentido al acontecer organizacional y social, pues es de las clasificaciones 
y la forma como se (re)presenta y proyecta la realidad que se emprenden acciones y se evalúa lo sucedido a partir del lenguaje común que proporciona la contabilidad que, como señala Alawattage (2011), es a la vez por excelencia un instrumento de integración social, de comunicación y de conocimiento, que hacen posible el consenso en el sentido del mundo social.

En un sentido análogo, Bourdieu entiende que las formas en que los sujetos representan y clasifican los diversos aspectos de la realidad

Producen simultáneamente 'realidad', tienen un poder performativo: resal$\tan$ o esconden unas propiedades para mostrar otras. Mediante palabras, consignas o las propias teorías, los clasificadores (los individuos portadores de habitus individual y de clase) construyen y destruyen simbólicamente la realidad (Tovillas, 2010, p. 80) ${ }^{9}$

Hay que mencionar, además, que la contabilidad puede ser enmarcada en dos perspectivas diferentes en la construcción de la realidad, en tanto forma de legitimación que permite (re)producir determinadas relaciones sociales y de poder (Alawattage, 2011), o como parte de un proceso de transformación de lo social, como mecanismo de subversión y de configuración

9 Respecto a las formas en que los contadores y auditores construyen su visión del mundo y en particular la forma en que valoran la información contable y los informes de auditoría se puede ver el texto "The Third Policeman: 'The true and fair view', language and the habitus of accounting” (Hamilton \& O'Hogartaigh, 2009). Hamilton y $\mathrm{O}^{\prime} \mathrm{Hogartaigh}$ en su escrito plantean que la visión de que la contabilidad y los informes de auditoría son razonables y transparentes (fidedignos) es una construcción social gestada desde criterios arbitrarios de racionalidad económica, estructurada a partir de unos intereses hegemónicos específicos. De allí que la educación desempeñe un papel preponderante en la legitimación y configuración de las subjetividades que van a guiar el actuar de los profesionales, y es mediante la obtención de dicho habitus y cualificación que los profesionales son autorizados para participar en el mercado laboral. A través del monopolio de la educación y la formación de nuevos auditores y contadores, se reproducen las relaciones sociales de las cuales fue producido su habitus, y con las cualificaciones que se obtienen de los claustros académicos, los estudiantes se dotan con un capital lingüístico para facilitarles el acceso a la lengua legítima y al capital cultural en la forma de un título académico y profesional. 
de otras lógicas a partir de las cuales entender las organizaciones y cambiar las estructuras de los campos y del espacio social ${ }^{10}$.

Desde la óptica de la reproducción y la legitimación del orden social, la contabilidad está asociada a la perpetuación de unas condiciones de poder, así, ésta hace parte activa en la reproducción del orden social caracterizado por jerarquías vertiginosas y formas desiguales de apropiación de los recursos, que al ser naturalizadas, son consideradas como normales y no problemáticas. ${ }^{11}$ Desde esta misma perspectiva señala Richardson (2009):

El papel de la contabilidad como institución de legitimación, es decir, el tener la capacidad de trasmitir legitimidad a las acciones, presupone y exige que el conocimiento contable y las instituciones por las que se promulga ese conocimiento, sean vistas como legítimas (p. 80) ${ }^{12}$.

La visión actual de la contabilidad, derivada de unas relaciones de poder singulares, se presenta como la forma legítima de representación de la realidad, a la vez que le da legitimidad a las prácticas de poder en la organización. Se entiende entonces el papel de la contabilidad como un medio por el que algunos agentes (por ejemplo grupos o clases sociales) buscan

10 De igual forma, es importante resaltar otro planteamiento de Gómez (2009) en relación con el papel de la contabilidad en la construcción de la realidad organizacional. Éste plantea: La condición tecnológica de la contabilidad implica que sus criterios intervienen directamente en la transformación del mundo. Esta transformación se da por su capacidad para intervenir por medio de los cálculos y dirigir la acción futura según rumbos definidos u objetivos particulares. La contabilidad crea un universo de símbolos y esquemas que, recreando los procesos económicos, transforman el mundo y nuestra imagen de él (p. 156).

11 En este sentido, plantea Tovillas (2010): Los sistemas simbólicos que son productos sociales y poseen al mismo tiempo un carácter interno y externo a los individuos y a los grupos, no son simplemente objetos e instrumentos de un conocimiento práctico por parte de ellos, sino que constituyen a su vez instrumentos de dominación política, en la medida en que fortalecen la integración cognitiva de un orden social de carácter arbitrario, esto es, no derivado de ningún principio extra social (biológico, psicológico o natural) (p. 83).

12 Véase también, respecto a la relación entre contabilidad y legitimación, el artículo "Los informes contables externos y la legitimidad organizacional con el entorno: Estudio de un caso en Colombia” del profesor Mauricio Gómez (2009). 
controlar y coaccionar a otros (Roberts y Scapens, 2009, p. 111). En esta misma dirección, afirma Alawattage (2011), "los sistemas simbólicos, como instrumentos estructurados y estructurantes: cumplen con su función política como instrumentos para legitimar la dominación" (p. 17). De esta forma, la violencia simbólica, que es la violencia que se ejerce sobre un agente social con su complicidad (Bourdieu y Wacquant, 1992), puede ser agenciada por la contabilidad y las prácticas de control que se derivan de allí (Miller y O'Leary, 2009) ${ }^{13}$.

Por otra parte, es importante resaltar que si bien las representaciones del mundo social guardan cierta complicidad con el orden establecido, éstas también podrían contener en sí un poder de subversión. En este sentido plantean Bourdieu y Wacquant (1992):

Los esquemas clasificatorios socialmente constituidos por medio de los cuales construimos activamente la sociedad tienden a representar las estructuras de las que surgen como naturales y necesarias, y no como la decantación históricamente contingente de un determinado balance de poder entre clases, grupos "étnicos" o géneros. Pero si aceptamos que los sistemas simbólicos son productos sociales que contribuyen a hacer el mundo, que no solo reflejan las relaciones sociales sino que ayudan a constituirlas, entonces, dentro de ciertos límites, es posible transformar al mundo transformando su representación (p. 38, 39).

Es a partir de esta capacidad de transformar el mundo, transformando sus representaciones, que se hace necesario pensar, bajo otros referentes, tanto la disciplina contable como la sociedad. A la par, dicho autor habla de la subversión herética, la cual pretende cambiar el mundo social cambiando la representación de la realidad; esta contienda hace parte de las "luchas de las representaciones", caso particular de las luchas de clases en las que se

13 Para ampliar más sobre las formas de control y de poder que se ejercen desde la organización desde una perspectiva foucaultiana, el lector puede remitirse al texto "La contabilidad y la construcción de la persona gobernable" (Miller y O'Leary, 2009), en particular el acápite IV: "La firma como el lugar en la construcción de la persona gobernable". 
disputa el monopolio del poder de hacer ver y hacer creer, hacer conocer y hacer reconocer, en resumen, de imponer (Arango, 2002, p. 115). Dicho de otra forma, -plantea Bourdieu (1985)-, la subversión política presupone una subversión cognitiva, una reconversión de la visión del mundo.

Pero si bien existe una lucha férrea y decidida en cuanto a la disputa en el ámbito de las representaciones del mundo social, insiste la profesora Arango (2002), "de nada sirve denunciar de un modo verbal la jerarquía: hay que esforzarse por cambiar realmente las condiciones que subyacen a su existencia, tanto en la realidad como en las mentes" (p. 114). Y en esta misma línea Gil (2003) recalca: "La contabilidad puede aplicarse para consolidar, legalizar y validar la realidad social, o ser usada como un instrumento de reflexión capaz de aportar al diseño de un escenario futuro distinto" (p. 26).

En la perspectiva planteada, los procesos de planeación y presupuesto hacen parte de las prácticas comunes dentro de los procesos de gestión organizacional, operan como estructurantes de las prácticas contables, en la medida en que influyen con la perspectiva de gestión que se tenga en la organización para producir cierto tipo de mensajes contables deseados o requeridos, los cuales, a su vez, permiten direccionar nuevas perspectivas o acciones de gestión, que se incorporan a la continuidad de la vida organizacional en nuevos procesos de planeación y proyección presupuestal para sostener la continuidad de las actividades, siendo así, también, estructuradas por la contabilidad.

La contabilidad, bajo esta óptica, no se encuentra por fuera de las luchas que tienen los agentes en el espacio social, los campos y las organizaciones; por el contrario, puede hacer parte integrante de la transformación de la realidad. Por ende, la contabilidad no puede ser vista de manera lineal ni estrecha, y mucho menos se le puede dar un carácter determinista, a priori, pues está ligada al devenir social y todo lo problemático que éste es. Si bien la contabilidad ha estado ligada por lo general a los poderes existentes en cada tipo de sociedad, puede jugar a su vez un poder de hacer parte de la subversión del mundo, produciendo lo que Bourdieu llama un "efecto teoría", "proponiendo una nueva manera de construir a los grupos sociales, como 
de construir nuevas instituciones o de modificar las existentes" (Tovillas, 2010, p. 78).

\section{ASOPROA o La Flor Insumisa}

ASOPROA, perteneciente al campo político ${ }^{14}$ y como parte del subcampo de las organizaciones campesinas ${ }^{15}$, está inserta en un ámbito de relacionamiento con vínculos y luchas comunes. Esto, de la mano de unas condiciones históricas y contextuales que establecen singularidades, que por las condiciones concretas de existencia en espacios de articulación regional han propiciado la lucha política desde lo rural que diferencia a ASOPROA de otras organizaciones campesinas.

Una serie de factores internos y externos y ciertos intereses económicos privados han incidido en el sector rural del país, y en el Oriente Antioqueño en particular, por ejemplo, la concentración de la propiedad y los cambios en el aprovechamiento de la tierra han insertado una lógica económica donde los proyectos y mega-proyectos han generado altos márgenes de rentabilidad para las grandes empresas, lo que ha devenido de la lógica de que la tierra debe estar en manos de agricultores "eficientes" que produzcan mercancías, las cuales puedan competir en el mercado internacional,

14 El campo político es el lugar donde se generan, en la competencia entre los agentes que ahíse encuentran, productos políticos, problemas, proyectos, análisis, comentarios, conceptos, acontecimientos, entre los cuales los ciudadanos ordinarios, en el estatuto de "consumidores", deben luchar, con posibilidades de malentendido tanto más grandes cuanto más alejados estén del lugar de producción (Bourdieu, 1982, p. 1).

15 La génesis del subcampo de las organizaciones campesinas, al interior del campo político, tiene como epicentro formas particulares de relacionamiento y lógicas singulares de construcción y visión del mundo desde lo rural, que difieren sobremanera de los marcos de percepción y acción preponderantes en el campo político (corrupción, intereses particulares sobre los generales, clientelismo, etc.). La unidad y solidaridad al interior del conjunto de las organizaciones campesinas tiene como base el capital social y político, que se gesta en la organización de sectores amplios del campesinado a partir de luchas, tanto en lo simbólico como en el de la acción y la movilización en busca de construir escenarios de vida y de producción diferentes a los imperantes. 
dejando así a los pequeños productores sin tierra y sumidos en la pobreza. Es este contexto el que permite entender la existencia de organizaciones que, en medio del conflicto, resistan en sus territorios y propendan por escenarios distintos de vida.

La génesis entonces del subcampo de las organizaciones campesinas, al interior del campo político, tiene como epicentro formas particulares de relacionamiento y lógicas singulares de construcción y visión de mundo, que difieren sobremanera de los marcos de percepción y acción preponderantes en este campo. La unidad al interior del conjunto de las organizaciones campesinas tiene como base el capital social y político, que se gesta en la organización de sectores amplios del campesinado a partir de luchas tanto en lo simbólico como en el de la acción y la movilización.

Con un capital social construido con los campesinos de la región, las Juntas de Acción Comunal, y de la mano de varias organizaciones nacionales (en particular la Corporación Jurídica Libertad) e internacionales, varios campesinos empiezan a idearse los cimientos de ASOPROA y formas alternativas de desarrollo.

En el 2002 algunos campesinos de la localidad decidieron organizarse a nivel regional para resistir a la crisis socio-política que se vivía en el Oriente Antioqueño a comienzos de siglo. Surge así una intención política que se constituye en relación con el conflicto y las condiciones de oprobio de la región en un estado determinado del juego político y, más precisamente, del universo de las técnicas de acción y de expresión que ofrece en un momento dado del tiempo (Bourdieu, 1982). En este sentido:

La Asociación de Pequeños y Medianos Productores del Oriente Antioqueño se crea como una propuesta organizativa desde y para los/las campesinos/ as del Oriente Antioqueño, en momentos donde la intensificación del conflicto armado había provocado el desplazamiento de muchas familias de sus territorios (ASOPROA, 2007) ${ }^{16}$.

16 Para conocer más sobre las condiciones históricas que dieron origen al proceso 
ASOPROA surge legalmente en el año 2004 con más de 200 asociados, definiéndose así como una organización campesina de base, buscando vincular grupos de producción agropecuaria, grupos de salud y de derechos humanos, las juntas de Acción Comunal, comités y demás organizaciones veredales y todos aquellos campesinos y campesinas que creen en el proceso organizativo para lograr desarrollar sus proyectos de vida (ASOPROA, 2007). En la actualidad, ASOPROA cuenta con 363 asociados de diferentes veredas del municipio de Cocorná y de la cuenca del Río Calderas, donde convergen los municipios de San Luis, Granada y San Carlos.

El capital social es el elemento fundante de la organización, pues se parte del trabajo común, y los lazos de unidad como los elementos que permiten tener unas condiciones diferentes de vida en la región. También, es el capital social el que permitiría conjugar fuerzas a quienes han quedado relegados de los beneficios generados por los megaproyectos, y a quienes la desigual distribución capitales ha marginado. Sin contar con amplio capital económico y sin un vasto capital cultural institucionalizado, los pequeños y medianos productores del oriente son presa fácil de comerciantes, emporios económicos (nacionales e internacionales), grandes terratenientes y el Estado, que cuentan con capitales que los respaldan y les dan ventajas frente al pequeño campesino y su producción.

Es así que la asociación se plantea como parte del proceso a largo plazo: La transformación de las relaciones de desigualdad económica, política, social y cultural imperantes en el Oriente Antioqueño mediante la construcción de propuestas alternativas de desarrollo que brinden bienestar y generen condiciones de dignidad para la comunidad campesina, en la búsqueda de autonomía e independencia frente al modelo económico impuesto en la región (ASOPROA, 2007: 23).

de constitución de ASOPROA, se remite al lector al video "Producir para RESISTIR/ ASOPROA" enhttp://www.youtube.com/watch?v=bhC2upxMXvI 
Producto de esas condiciones históricas concretas se forman habitus, conjuntos de disposiciones que permiten a los campesinos entender su realidad y afrontarla. Tal como lo enuncian Bourdieu y Wacquant (1992), "los agentes sociales son el producto de la historia, de la historia del campo social en su conjunto y de la experiencia acumulada por un trayecto dentro de un subcampo específico" (p. 199). Vistas así las cosas, el habitus de clase inmerso en los socios de ASOPROA se construye como resultado de la lucha por el territorio y la preservación del acumulado histórico, producto de las condiciones de la región y del país. Por tanto, este acumulado histórico, en sus diferentes dimensiones, hace parte de la vida de quienes colectivamente construyen y resisten desde y en ASOPROA.

Es a partir de esas apuestas comunes ligadas a las condiciones de vida de los pequeños y medianos productores rurales, donde se definen las estrategias en juego, de ese sentido colectivo de construcción social como forma de resistencia y proyecto de vida, configurando así proyectos alternativos por medio de los cuales se propende por la transformación de las formas de vivir en el campo, encarnando en la colectividad formas de concebir la vida y el territorio desde un marco diferente al imperante en la región. La lucha se da también desde lo simbólico y de las formas de percepción, por lo cual desde la organización se busca consolidar las bases para que los socios puedan percibir de forma diferente sus problemas a como lo habían hecho antes.

Lo anterior se evidencia en la discusión dada en la Junta Directiva de ASOPROA el 12 de marzo de 2011 respecto al concepto de desarrollo, pues algunos integrantes de la Junta consideraban que la utilización de esta palabra hacía referencia y seguía el juego a las lógicas del modelo de "desarrollo" imperante en la región, por lo cual se debía desechar la noción hegemónica de desarrollo. Al final, se concluyó que era necesario hacer una ruptura con ese modelo y concepción, y hablar más bien de organizar planes de desarrollo alternativos, para significar así la ruptura con la concepción de desarrollo que les habían impuesto. En este sentido, estructurar otras formas de pensarse y actuar ante la realidad es una forma en que se 
pretende combatir la violencia simbólica que se ejerce en el campo político y que perpetúa las relaciones de poder y dominación inscritas en el campo.

Es esa historia común incorporada en los cuerpos y en las mentes de quienes hacen parte de ASOPROA la que los convoca a un tipo particular de Illusio, es decir, un tipo particular de interés, a partir del cual el estar inmersos en un proceso social tiene sentido, hasta el punto de sacrificar a veces tiempo, recursos propios y en ciertos casos hasta la vida misma en función de la organización y la lucha al interior del subcampo de las organizaciones campesinas y del campo político.

Si bien en el marco general de la organización la Illusio es definida a partir de la lucha política y la preponderancia de lo social, los intereses que convocan a todos los asociados pueden no ser en todos los casos los mismos. Es decir, las desiguales condiciones de existencia de cada individuo pueden dar un sentido del "juego" diferente al que prima en el subcampo y que lo organizativo, por ejemplo, sea simplemente un medio por el cual el asociado busque adquirir simplemente un mayor capital económico, lo que puede dar pie a disputas y tensiones en la organización. Un ejemplo de esto se evidencia cuando algunos campesinos deciden asociarse por los recursos que podrían obtener del fondo común o de los recursos que vienen de ONGs nacionales e internacionales, más que por los procesos sociales y políticos que representa estar en ASOPROA.

Por otra parte, en cuanto a las formas de relacionamiento propias de la asociación, y a la estructura de funcionamiento, es de anotar que la organización opera a partir de diferentes instancias con una estructura horizontal. La Asamblea General de Socios "es la máxima instancia de decisión de la organización, allí se definen las políticas y programas de la asociación y se elige la Junta Directiva" (ASOPROA, 2007). Son entonces los campesinos, desde la Asamblea General de Socios y las diversas actividades de la asociación, quienes evalúan y definen los asuntos y proyectos de la organización. Así mismo, son la Junta Directiva (conformada por Presidente, Vicepresidente, Secretario, Tesorero y Vocal) y los diferentes 
Comités dentro de la asociación los que deben garantizar la ejecución de los planes definidos por los socios de manera colectiva (ASOPROA, 2007).

Figura 1. Estructura Organizacional ASOPROA

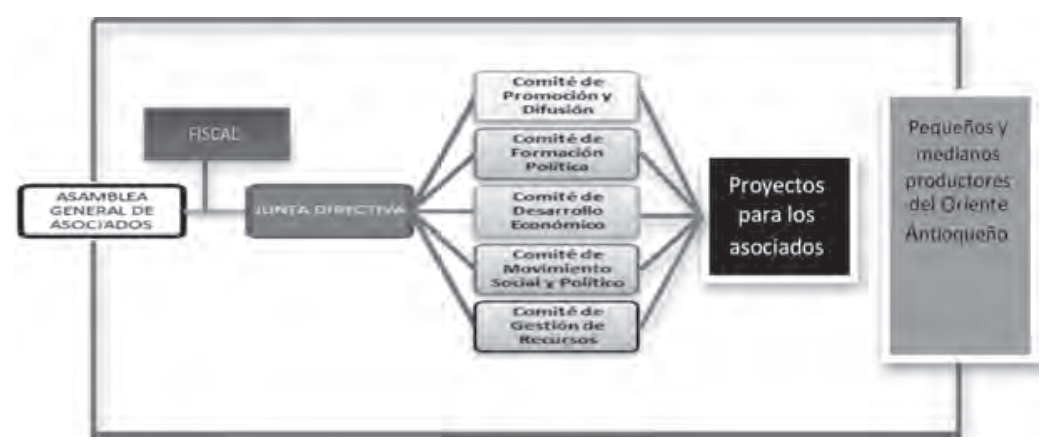

Fuente: ASOPROA

ASOPROA se define entonces a sí misma en su misión como: una organización campesina, social y política del Oriente Antioqueño, que busca transformar la realidad en que vivimos, defender los intereses de la comunidad campesina e incidir en el desarrollo rural con propuestas alternativas que contrarresten el modelo impuesto en la región. A partir de allí, define su accionar, consignado en cinco objetivos estratégicos (Tabla 1), que a su vez se concretan en proyectos y acciones.

Es de entender que la construcción que se lleva a cabo tiene incidencia en dos aspectos interconectados, uno son las condiciones materiales de los campesinos, su nivel de vida; $y$ el otro tiene que ver con las formas de percepción y el habitus, es decir, con la forma como los campesinos se perciben a sí mismos, su realidad y a la misma asociación. Las diferentes estrategias que la asociación se plantea implican cambios o transformación de capitales, donde las disímiles "transacciones" se establecen a partir de diversas necesidades y prioridades. El conservar los capitales existentes y aumentarlos se convierte entonces en algo primordial, pues es a partir de los capitales que la asociación puede adquirir, intercambiar o transformar que se podrá llevar a cabo el proyecto social, político y económico planeado para la región. 
Tabla 1. Objetivos estratégicos ASOPROA

\begin{tabular}{|c|c|}
\hline OBJETIVO & DESCRIPCIÓN \\
\hline $\begin{array}{l}\text { DESARROLLO } \\
\text { ECONÓMICO }\end{array}$ & $\begin{array}{l}\text { Fomentar la economía campesina, el bienestar y la seguridad } \\
\text { alimentaria de las comunidades rurales a través de incentivos } \\
\text { económicos para la producción de alimentos, insumos orgánicos, } \\
\text { concentrados alternativos y diversas estrategias de comerciali- } \\
\text { zación y economía solidaria como centros de acopio, tiendas } \\
\text { comunitarias, redes directas con consumidores, etc., para lograr } \\
\text { autonomía campesina, la defensa y la permanencia en el territo- } \\
\text { rio, buscando el beneficio directo para los afiliados de ASOPROA. }\end{array}$ \\
\hline $\begin{array}{l}\text { DINAMIZACIÓN } \\
\text { DEL MOVIMIENTO } \\
\text { POLÍTICO DEL } \\
\text { ORIENTE }\end{array}$ & $\begin{array}{l}\text { Construir una agenda política con la participación de diferentes } \\
\text { organizaciones comunitarias de la región a través de asambleas, } \\
\text { reuniones con líderes representativos y el apoyo de organizacio- } \\
\text { nes sociales que respaldan la agenda política para dinamizar la } \\
\text { propuesta de movimiento político en el Oriente Antioqueño. }\end{array}$ \\
\hline $\begin{array}{l}\text { GESTIÓN Y } \\
\text { ADMINISTRACIÓN } \\
\text { DE RECURSOS }\end{array}$ & $\begin{array}{l}\text { Generar procesos de gestión política y económica a través } \\
\text { de alianzas con organizaciones sociales locales, nacionales e } \\
\text { internacionales, con agencias de cooperación y de procesos } \\
\text { administrativos consolidados para una sostenibilidad en su } \\
\text { accionar socio-político. }\end{array}$ \\
\hline $\begin{array}{l}\text { FORTALECIMIENTO } \\
\text { INTERNO }\end{array}$ & $\begin{array}{l}\text { Promover la cualificación política e ideológica de los asociados } \\
\text { a través del mejoramiento de los niveles de comunicación entre } \\
\text { directivos y afiliados, el fortalecimiento de los espacios de forma- } \\
\text { ción, discusión y decisión para el reconocimiento de ASOPROA } \\
\text { como referente organizativo en la región. }\end{array}$ \\
\hline
\end{tabular}

Fuente: Plan Estratégico ASOPROA 2008-2010 (ASOPROA, 2007).

En el contexto de los objetivos planteados por la asociación se construyen planes de acción por periodos de tres años. Para el año 2011, la Junta Directiva se encontraba en el proceso de construcción de la planeación estratégica para los años 2012-2014, para lo cual convocaba a los asociados a diferentes talleres en los centros zonales bajo la siguiente premisa:

Queremos que en el segundo semestre todos y todas las asociadas se vinculen con sus sueños, propuestas y participación activa en lo que será el accionar de nuestra Asociación a tres años más (ASOPROA, 2011).

La planeación propuesta por ASOPROA contempla los diferentes elementos que incorporan tanto lo que hay que hacer como los medios para 
conseguirlo. Las propuestas económicas, por ejemplo, van ligadas a lo social, lo político y la formación; por tanto, los recursos económicos que obtiene la asociación por diferentes fuentes, no son un fin en sí mismo, son un medio para que se puedan potenciar los otros capitales y los proyectos de los mismos campesinos. Un ejemplo de esto se puede ver en la Tabla 2, en la cual se evidencian, en el objetivo de "dinamización del movimiento político en Oriente", las apuestas que la asociación tiene respecto a esto.

Es de anotar, como se mencionaba anteriormente, que los criterios que definen el actuar estratégico y qué capitales son más relevantes que otros, dependen de las características del subcampo, de las luchas que se llevan a cabo al interior del campo político (en particular en el sector rural), y del habitus de clase e illusio que delimitan las prioridades y las apuestas de la organización. ASOPROA, por fundamentarse en el capital social y por su lógica y estructura interna, da diversas relevancias a cada capital, y cada capital incorporado en la asociación busca ser utilizado de manera coherente con los parámetros sociales de ésta y sus objetivos.

Tabla 2. Ejemplos de elementos estratégicos del plan ASOPROA 2008 - 2010

\section{DINAMIZACIÓN DEL MOVIMIENTO POLÍTICO IMPACTO DEL ORIENTE}

\begin{tabular}{|c|c|}
\hline $\begin{array}{l}\text { Promover la cualificación política e } \\
\text { ideológica de los asociados a través }\end{array}$ & $\begin{array}{l}\text { A diciembre de 2010, las comunidades campesinas } \\
\text { de San Carlos, San Luis, Granada y Cocorná conocen } \\
\text { ASOPROA y sus diversos programas y propuestas } \\
\text { de trabajo. }\end{array}$ \\
\hline $\begin{array}{l}\text { del mejoramiento de los niveles de } \\
\text { comunicación entre directivos y } \\
\text { afiliados, el fortalecimiento de los } \\
\text { espacios de formación, discusión } \\
\text { y decisión para el reconocimiento }\end{array}$ & $\begin{array}{l}\text { A diciembre de } 2010 \text {, el } 80 \% \text { de los asociados de } \\
\text { ASOPROA conoce las apuestas políticas y alterna- } \\
\text { tivas de desarrollo definidas por la Asociación para } \\
\text { sus afiliados y comunidades campesinas. }\end{array}$ \\
\hline $\begin{array}{l}\text { de ASOPROA como referente } \\
\text { organizativo en la región. }\end{array}$ & $\begin{array}{l}\text { A diciembre de } 2010 \text {, el } 30 \% \text { de los asociados de } \\
\text { ASOPROA cuenta con niveles de formación política } \\
\text { que le permite interlocutar con entidades estatales, } \\
\text { empresas y ONGs para defender los intereses de la } \\
\text { comunidad campesina y posicionar sus apuestas y } \\
\text { propuestas a nivel regional. }\end{array}$ \\
\hline
\end{tabular}

Fuente: Planeación ASOPROA 2008-2010 (ASOPROA, 2007). 


\section{La articulación de la planeación y el presupuesto en ASOPROA}

Para la presente investigación se han identificado la planeación y la presupuestación como elementos que permiten evidenciar el papel diferenciado y diferenciador de la contabilidad en organizaciones en las que prima lo social y político ante lo económico. Es necesario aclarar que, si bien este aspecto no podría considerarse el único en términos contables, permitirá entender lo contable desde otras lógicas. Se asume dicho aspecto como el más pertinente para marcar una diferencia, en la cual se pueda vislumbrar cómo prácticas similares a organizaciones económicas con fines de lucro son asumidas desde ópticas diferentes por las condiciones de la organización y el subcampo al que se articula, pues la lógica inmersa en él deslinda con la racionalidad instrumental de las organizaciones con fines de lucro, en las cuales se privilegia lo rentable a lo colectivo y comunitario.

De esta forma, se pretende evidenciar cómo la planeación y el presupuesto, al ser sistemas simbólicos estructurados y estructurantes, se constituyen en arbitrarios históricos y culturales a partir de unas necesidades concretas, y son los contextos diferenciados los que permiten evidenciar el poder simbólico disímil de la contabilidad. La eficacia del poder de lo contable al interior de las organizaciones, como se mencionaba antes, debe ser entonces analizada desde las diversas lógicas de los campos y subcampos a los cuales se adscribe, con sus habitus, illusio, relaciones de poder, estrategias y preponderancias de capital.

\subsection{La planeación y el presupuesto}

Las lógicas imperantes del espacio social privilegian la medición de todo en términos de eficiencia y rentabilidad, esto ha ocasionado que la contabilidad sea asociada a las labores de registro y análisis de la información monetaria y financiera. En contraste, en ASOPROA existen dinámicas totalmente divergentes a las organizaciones del campo económico a las cuales, por lo general, se asocia lo contable. 
Entender la forma en que se configura el presupuesto en ASOPROA implica concebir un distanciamiento con la racionalidad intrínseca del campo económico. Es decir, la planeación y el presupuesto se construyen desde los fundamentos propios de la organización. Como lo manifiesta el asesor económico de ASOPROA (Comunicación personal, dada el 5 marzo de 2012), en la asociación se privilegia lo político a lo económico (...) "Allí se debe privilegiar lo político pues esto debe estar por encima de que estos eventos no dejan rentabilidad. El dinero no opera por encima del fin político". Es así como la construcción del presupuesto plantea una mirada a la luz del habitus de clase de la organización como de las disputas, las tensiones al interior del campo político y sus manifestaciones en lo rural.

La construcción del presupuesto parte inicialmente de la planeación, la cual se construye para un periodo de tres años. A partir de los objetivos generales definidos por la organización (Tabla 1), cada año se establece un presupuesto para llevar a cabo la planeación. Con ésta, ASOPROA manifiesta su actuar estratégico, el cual permite entrever cómo en la lucha al interior del campo político los actores sociales marginados gozan de autonomía, más allá de las relaciones de dominación y estructuras de poder, para la resistencia y la elaboración de estrategias (Alawattage, 2011, p. 15). En ese sentido, la planeación 2008-2010 de la asociación plantea:

Para toda organización social y política es indispensable pensarse en su quehacer a largo plazo, más aún cuando las problemáticas que quiere transformar son estructurales; para lograrlo debe plantear estrategias que le eviten caer en el desgaste o la desesperanza de que lo que hace no aporta al cambio de la realidad. (ASOPROA, 2007).

De esta forma, la construcción del presupuesto se concreta desde los cuatro objetivos estratégicos propuestos por la asociación y del impacto que busca por cada periodo (ver Tabla 2), a su vez, de esto se derivan estrategias para el cumplimiento de los objetivos; de las cuales se desprenden acciones, y luego, con un grado de concreción mayor, se definen actividades con sus respectivas fechas de realización, los responsables y los costos asociados (Tabla 3). 


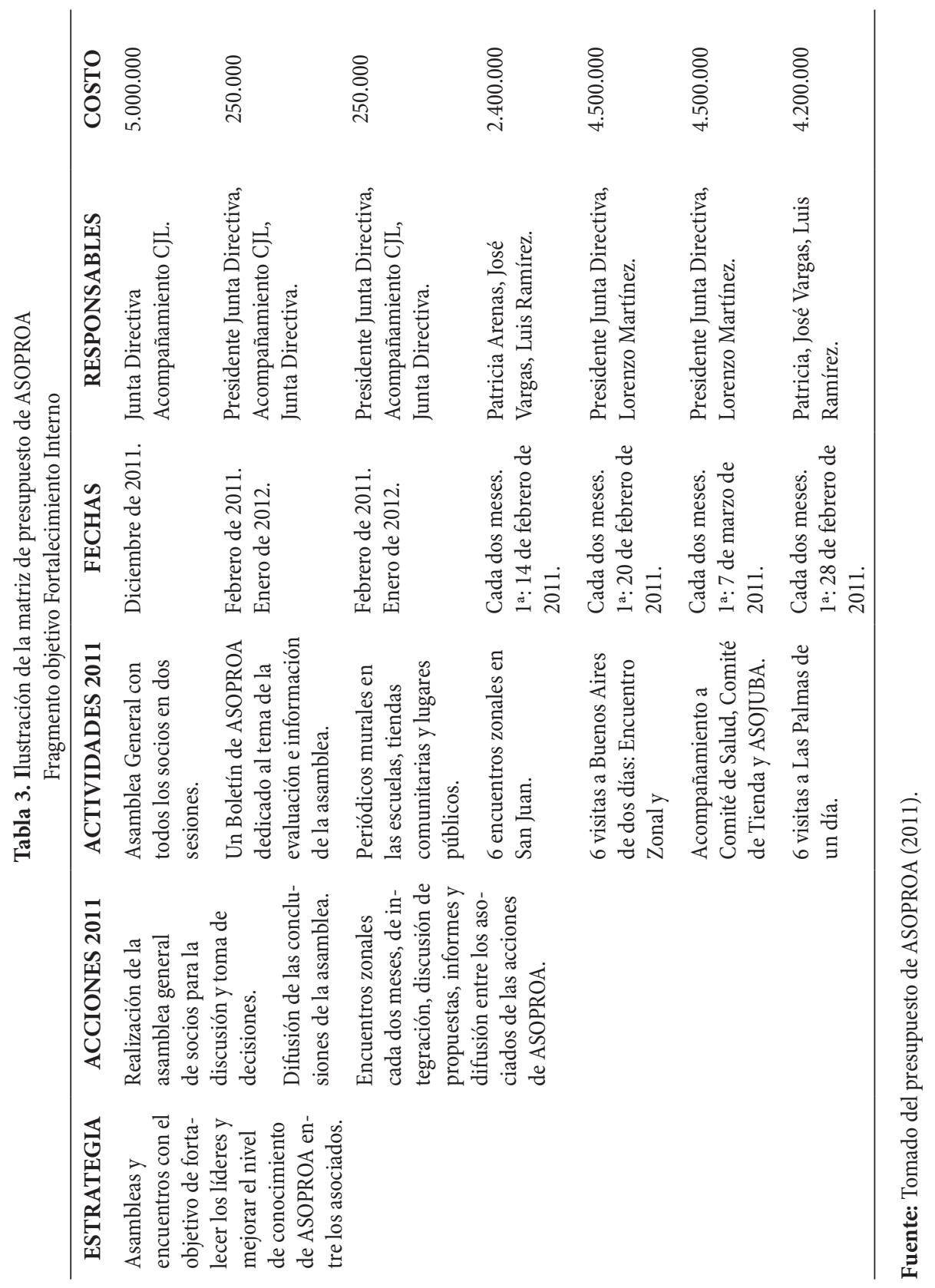


La construcción del presupuesto, según lo enuncia el presidente de la asociación, es el siguiente:

Se realiza una evaluación del estado de ASOPROA, es decir ¿cómo está en este momento? ¿qué es lo que se proyecta? En ese proceso se evidencia cuáles son las fortalezas y cuáles son las debilidades, y es de acuerdo con éstas últimas que se hace la respectiva programación, se trazan actividades y a cada actividad se le asigna, así sea de manera teórica, unos costos, y de esto es que sale un resultado de recursos para intervenir (Comunicación personal, dada el 14 de abril de 2012).

Es así como la planeación y el presupuesto, al ser un sistema simbólico y un arbitrario histórico y cultural, ayudan a estructurar la organización e influyen directamente en la forma en que los asociados interpretan y actúan ante la realidad, pues al ser ésta proyectada en mensajes, permite encaminar procesos, guiar la política, evaluar y controlar el accionar de ASOPROA, y a su vez posibilita conjugar la prospección de la asociación con las necesidades de recursos monetarios para la consecución de sus objetivos.

Se evidencia entonces cómo la contabilidad, por medio de la planeación y el presupuesto, participa de manera activa en la producción de las interacciones sociales, brindando información para que los asociados la usen e interpreten de manera individual en tal proceso de gestión y posibilitando la creación de consensos entre los integrantes de ASOPROA acerca de sus metas, planes e incidencia en el campo político y el espacio social.

Bajo las lógicas de ASOPROA, el presupuesto privilegia los resultados esperados en torno al bienestar de la comunidad, no limitándose ese alcance a los vinculados a la asociación, puesto que el logro de sus objetivos impacta positivamente al sector campesino del Oriente Antioqueño; por esto mismo, asevera el asesor económico de la asociación: "la producción y el proceso social de ASOPROA no depende netamente de la rentabilidad; si fuera así, no tendría sentido" (Comunicación personal, dada el 20 de marzo de 2012).

Lo anterior se muestra, por ejemplo, en el hecho de que la construcción del presupuesto no lleva ninguna estrategia o actividad tendiente a 
conseguir recursos o a obtener ingresos (lo que no quiere decir que esto no sea importante). Posterior al diseño del plan y el presupuesto, se financian proyectos con los recursos propios de la asociación y se gestiona con diferentes organizaciones para financiar los proyectos para los cuales no se tienen recursos. En el caso de la primera planeación, realizada en 2007, comenta el presidente de la asociación que el "plan tuvo un retraso de un año porque no resultaron recursos, pero finalmente se pudo iniciar". Para la consecución de recursos, entonces, ASOPROA utiliza el capital social y simbólico que ha construido con el tiempo, por lo cual diversas organizaciones internacionales, sindicatos y ONGs financian y apoyan diversos proyectos de la asociación proporcionando recursos económicos, personal para capacitaciones y acompañamiento, entre otros.

Esta misma racionalidad implica que haya una valoración desde parámetros diferentes de lo que constituyen los "costos" y los "beneficios", definidos desde lo relevante que es cada acción en la construcción de otras formas de relacionamiento y de poder en la región. En el caso de ASOPROA, las líneas de acción deslindan con los parámetros de relevancias desde lo crematístico, para darle prioridad al capital social y político, que allende de presupuestar unos costos relativos, está presupuestando también cómo se pueden desplegar diversos tipos de capitales para escalar en la configuración de fuerzas que les permitan tener mayor incidencia en el campo político y transformar las condiciones del espacio social, como lo son, por ejemplo, el boletín y los encuentros zonales (ver Tabla 3), con los cuales se afianzan los lazos de unidad y se incentiva a más gente a participar de la asociación (incidiendo en el capital social), a la vez que se forma políticamente a los asociados (afectando el habitus y el capital cultural incorporado).

Lo que sí adquiere relevancia a través de la planeación y el presupuesto es la evaluación y seguimiento de las acciones propuestas, y que éstas sí arrojen como resultado el aumento del capital social, económico y cultural, lo que a su vez se espera que incida en las diferentes luchas en el campo político, de esto se define que el actuar organizacional está incidiendo en la región y que la lucha vale la pena. 
En términos de Alawattage (2011) se podría aseverar que el presupuesto funciona como un medio simbólico a través del cual las propiedades estructurantes del campo (en este caso el campo político, y en particular el subcampo de las organizaciones campesinas) son cognoscibles, comunicadas, reproducidas o transformadas en un conjunto de disposiciones que orientan, día a día, las prácticas de trabajo y de resistencia. Esto debido a que desde la construcción del presupuesto, derivado de la activa participación de los asociados (lo que a su vez implica una lucha por lo que se hace y su sentido), los intereses colectivos se ven reflejados en el quehacer de la organización, constituyendo la creencia que vincula los intereses de los individuos con los de la colectividad, es decir, que el cumplimiento de la planeación establecida derivará en beneficio de la comunidad; por ende, contribuye a impulsar el trabajo de los asociados en torno a ASOPROA, para así transformar las visiones de mundo y las condiciones de existencia que se reproducen en el espacio social. A través de la información que arroja todo el proceso de planeación y presupuestación, se pretende que los asociados incorporen la illusio de la asociación, transformen su pensamiento y consideren valiosos los intereses y luchas que allí se gestan.

En este sentido, el habitus, imbricado en la planeación y el presupuesto, posibilita la conjugación de intereses, pero configura un lenguaje común y un sistema de valores con los que se define lo pertinente, lo apropiado y lo viable. Habitus que involucra todos los procesos de la organización, desde la construcción de la planeación hasta su puesta en marcha, seguimiento y evaluación. En consecuencia, podría afirmarse que el habitus de clase que existe en ASOPROA y la illusio (sentido del juego) configuran un conjunto de disposiciones a partir de las cuales se le da sentido al futuro desde lo colectivo. Podría afirmarse entonces, siguiendo a Tovillas (2010), que la planeación y el presupuesto permiten que los distintos individuos de la asociación puedan referirse a las mismas oposiciones (por ejemplo, bueno/ malo, importante/intrascendente, rico/pobre, etc.) para descifrar el mundo social y su posición en este mundo.

Teniendo presente lo anterior, se debe considerar la planeación y el presupuesto desde dos intereses básicos: la movilización a partir de la 
orientación política y la evaluación, seguimiento y control del accionar organizacional. Esto se evidencia en la presentación de la planeación estratégica de la asociación cuando se menciona que: "El proceso de planeación de ASOPROA parte del interés de la Junta Directiva por aportar en la orientación política de la Asociación y evaluar el trabajo que hasta la fecha se ha realizado" (ASOPROA, 2007).

En lo concerniente a la movilización, la asociación en su planeación plantea: "lo más importante de este texto es que cada uno y una se comprometa con la transformación de las condiciones de exclusión y pobreza a que están sometidos tanto los asociados como los campesinos del Oriente Antioqueño" (ASOPROA, 2007).

La planeación y el presupuesto sirven así de guías para el accionar; en él se plasman los deseos construidos por todos los asociados en cuanto al quehacer de ASOPROA, lo cual posibilita que se comprometan y movilicen en torno a las causas, ya que desde aquí se empiezan a sentir identificados y vinculados a la organización, conjugando finalmente el actuar de la asociación con sus objetivos políticos, sociales, culturales y económicos. La movilización implica entonces la puesta en marcha de diversos tipos de capitales, desde lo cual interviene lo simbólico y las luchas en el terreno de entender el territorio, las relaciones de poder y la posición de los campesinos ante dichas relaciones.

La movilización, como lo mencionaba Bourdieu, parte de las mismas dinámicas del campo y de sus contradicciones, pero sobre todo, de las luchas por las formas de percepción producto del habitus que están en constante dinamismo; de allí, por ejemplo, que la asociación desde la Junta Directiva y sus comités insistan en realizar constantemente encuentros zonales, capacitaciones, evaluaciones de lo sucedido. Desde aquí que se entienda con Bourdieu que las apuestas en el mundo político siempre sean dobles, es decir, que se manifiestan como combates por ideas, pero como éstas no son completamente políticas hasta cuando se vuelven ideas-fuerza, son también combates por poderes (Bourdieu, 2000b). 
Por otra parte, la evaluación, seguimiento y control de lo que desde la asociación se definió como relevante en el plan y el presupuesto, se hace por lo general a finales y a comienzo de cada año desde la Junta Directiva, los Comités y la Asamblea de Socios. El habitus, aquí, se hace de nuevo presente para dar sentido a lo sucedido, y es a partir de éste que se valora el pasado. Desde una mirada retrospectiva, se compara lo que se había planeado, lo que se hizo, con los resultados obtenidos. Se hace así un balance de lo que se ha conseguido y sus problemas, en busca de mejorar en el siguiente año. De esta forma, como lo señalan Roberts y Scapens (2009):

La práctica contable involucra la comunicación de nociones, y es solamente sobre la base de estas nociones que se le confiere sentido a lo sucedido. La elaboración del presupuesto es quizás el ejemplo más obvio de cómo lo que ha sucedido está bajo evaluación constante, en términos de lo que se espera que ocurra (p. 110).

De lo anterior que se pueda hablar de la planeación y el presupuesto como una estructura estructurante y como arbitrario histórico y cultural, pues es a partir de allí que se derivan los juicios sobre lo acaecido.

En concordancia, los diversos capitales y sus jerarquías dentro de la asociación y el habitus se relacionan de manera dialéctica para construir, desarrollar, evaluar y controlar las diversas estrategias, y de esta conjugación es posible entender las lógicas a partir de las cuales se construye el presupuesto, con sus diversas inversiones de capital y los resultados esperados. En congruencia, la contabilidad en este asunto sirve como medio para dirigir y concretar el potencial social de la organización (Roberts y Scapens, 2009).

Lo anterior permite entonces reafirmar el planteamiento de Oakes, Townley y Cooper (2009), de que las diferentes formas de capital inscritas en la organización contribuyen a entender la configuración de las prácticas de gestión, la evaluación y la rendición de cuentas, las posiciones organizacionales, las responsabilidades y el funcionamiento. Y en este caso, se puede evidenciar que la planificación y el presupuesto de los diferentes tipos de capital ofrecen a los individuos un vocabulario de motivos y un sentido de 
identidad, y generan valores y conceptos preponderantes sobre el trabajo y la importancia organizacional.

Más allá de la visión de objetividad y neutralidad muy común en la corriente ortodoxa contable, hay que poner el acento en el papel de la contabilidad en la construcción de la realidad, volviendo la mirada a lo social y lo popular, pues desde un sentido ético y político, nos enfrentamos a la encrucijada de la reproducción o la transformación del orden social. Respecto a esta encrucijada, es necesario reafirmar el sentir de Bourdieu de que "los intelectuales (entendiendo por ello a los artistas, escritores y científicos que se comprometen en una acción política) son indispensables para la lucha social, especialmente hoy, dadas las formas completamente nuevas que adquiere la dominación" (Bourdieu, 2001, pp. 39, 40).

\section{Conclusiones}

El entendimiento de la dinámica social, y en particular de los campos organizacionales, es una tarea compleja, y mucho más cuando se considera de manera dialéctica la realidad. Resaltar la complejidad de la sociedad implica el reto de tener los elementos que develen todas sus tonalidades y matices. En este proceso complejo, Pierre Bourdieu propone una serie de elementos teóricos que permiten dar pasos importantes hacia la construcción del conocimiento social. Es importante entonces resaltar la riqueza conceptual que aporta dicha teoría al conocimiento de la realidad social y organizacional (Oakes, Townley \& Cooper, 2009).

La teoría de Bourdieu permite entender las organizaciones en su dinámica y sus tensiones. En el actuar organizacional se vinculan las relaciones de poder y la distribución de los recursos (o tipos de capitales) con las subjetividades e intereses diversos de los agentes. En este caso, los conceptos de Campo, Capital, habitus, illusio y estrategias posibilitan, desde una mirada relacional, captar el dinamismo de las prácticas organizacionales.

Teniendo presente lo anterior, existen grandes repercusiones en el entendimiento de la contabilidad, pues esto implica una comprensión de 
la misma a partir del contexto organizacional y social en el cual se desenvuelve. En este sentido, se requiere un conocimiento de las condiciones concretas en las que opera la disciplina y se fundamentan sus prácticas. De este modo, los conceptos de Bourdieu se conjugan para permitir tanto el conocimiento organizacional como las condiciones en las cuales opera, adquiere sentido y se recrea lo contable.

En consonancia, la contabilidad, vista como una construcción social y como parte de la objetividad de segundo orden, se erige como un sistema simbólico, que a partir de intereses históricos específicos se constituye en un arbitrario histórico y cultural, en el cual están inmersas las relaciones de poder, estructuras y jerarquías que caracterizan los campos, los subcampos y las organizaciones, con sus luchas e interacción con otros campos. De esta forma, señala Alawattage (2011), la contabilidad, como estructura estructurada y estructura estructurante, cumple las veces de ser un particular sistema simbólico en el cual se conjugan funciones de comunicación, cognición y poder.

Pero lo contable puede ser entendido tanto en la reproducción como en la transformación de la realidad, rescatando su papel en la construcción de ésta última. En este sentido, la investigación permite evidenciar el papel diferenciador de la contabilidad a partir de intereses divergentes a los dominantes en el mundo empresarial. De esta forma, se comprende su rol en la resolución de problemas de ASOPROA. Esto permite evidenciar las divergencias en cuanto a la lógica misma de la organización, como la manera en que la contabilidad se articula a ellas. Es decir, las prácticas contables adquieren sus singularidades por la peculiaridad de la organización a la que se articula y a las lógicas de los campos y subcampos a los que éstas se adscriben.

La contabilidad se conjuga entonces a partir de la estructura de ASOPROA, y existe en relación al habitus de clase, tipos de capital, estrategias e illusio inmersos en ésta. Las relaciones de poder que allí se tejen desde los asociados y sus instancias administrativas hacen partícipe a la planeación y al presupuesto del juego al que le apuesta la organización, 
donde lo social termina siendo prioritario, subordinando asílo económico a los proyectos políticos en el largo plazo.

Por ende, la contabilidad, y en particular la planeación y el presupuesto, hacen parte de esa subversión herética de la que habla Bourdieu, en la cual nuevas lógicas de entendimiento y representaciones del mundo social se hacen presentes como elementos indispensables para la transformación de la realidad. Así es como lo financiero está subordinado a lo social.

Asimismo, el plan y el presupuesto permiten entender las lógicas intrínsecas de la organización, de lo que se considera relevante a nivel global y en aspectos concretos como las acciones planteadas. En este sentido, la contabilidad, más que permitir una (re)presentación o proyección de la realidad, permite entrever la racionalidad que guía la propensión (marcadas por el habitus de clase) hacia determinadas subjetividades y formas de comportamiento. En este caso, el habitus y los tipos de capital hacen parte de la racionalidad que estructura el accionar de la organización, lo que permea diametralmente a la contabilidad, en las cual se evidencian algunos de los elementos estratégicos que permiten, según los criterios organizacionales, incidir en las relaciones de poder al interior del campo político.

En el caso investigado, la contabilidad es vista en sus vínculos con la planeación y el presupuesto para entender las lógicas diferentes que se generaban en el campo particular analizado, pero sería importante, desde una mirada más amplia, pensar en nuevos referentes en los cuales la contabilidad puede intervenir en las realidades organizacionales más allá de lo financiero, subversión herética necesaria en la teoría y práctica contable, pues esto permitirá observar y construir la sociedad desde otros referentes.

\section{Referencias bibliográficas}

Agudelo, L. (2010) Campesinos sin tierra, tierra sin campesinos: territorio, conflicto y resistencia campesina en Colombia. En Revista Nera, 16, 81-95. Extraído el19 de marzo de 2012 de http://www2.fct.unesp.br/nera/revistas/16/11_patino.pdf 
Alawattage, C. (2011) The calculative reproduction of social structures - The field of gem mining in Sri Lanka. Critical Perspectives on Accounting, 22 (1), 1-19. Arango, L. (2002) Sobre dominación y luchas: clase y género en el programa de Bourdieu. Revista Colombiana de Sociología. 01 (07), 99-118.

Asociación de Pequeños y Medianos Productores del Oriente Antioqueño [ASOPROA]. (2011). Boletín formativo No. 11. Manuscrito no publicado. . (2011). Estudio de mercadeo en veredas de Cocorná, Granada y San Luis. Antioquia: Corporación Jurídica Libertad. . (2009a). Cómo queremos vivir en el territorio y qué requerimos para vivir bien. Centro zonal el molino, Cocorná. Antioquia: Corporación Jurídica Libertada.

. (2009b).Transferencias, equidad y desarrollo regional. Extraído el 20 de marzo de 2011 de http://cjlibertad.org/files/Transferencias,\%20equidad\%20 y\%20desarrollo\%20regional.pdf

. (2008). Producir para RESISTIR/ASOPROA, Recuperado el 21 de febrero de 2012 de http://www.youtube.com/watch?v=bhC2upxMXvI . (2007). Plan estratégico 2008-2010. Manuscrito no publicado. . (2006). Fortalecimiento de la organización campesina para la prevención del desplazamiento y el impulso al desarrollo local. Antioquia: Corporación Jurídica Libertad.

Bourdieu, P. (2007). El sentido práctico. Buenos Aires: Siglo XXI Editores. . (2002a). Estrategias de reproducción y modos de dominación. Colección Pedagógica Universitaria 37-38, 1-21. . (2002b). Campo de poder, campo intelectual: itinerario de un concepto. Argentina: Editorial Montressor.

. (2001). Contrafuegos 2: Por un movimiento social europeo. Barcelona: Anagrama.

. (2000). Sobre el campo político. Recuperado el 21 de febrero de 2012 de http://mt.educarchile.cl/MT/jjbrunner/archives/BOURDIEU_campo-politico. pdf

. (2000a). Las formas del capital. Capital económico, capital cultural y capital social. En Bourdieu, P. Poder, derecho y clases sociales (131-164), Barcelona: Desclée. . (2000b). Cosas dichas. Barcelona: Editorial Gedisa. 
. (2000c). Sobre el poder simbólico. En Intelectuales, política y poder, traducción de Alicia Gutiérrez, Buenos Aires, UBA. Eudeba, 65-73.

. (1999). Entrevista a Pierre Bourdieu por Pepe Ribas. Recuperado el 21 de febrero de 2012 de http://ddooss.org/articulos/entrevistas/Pierre_Bourdieu. htm)

. (1997). Razones prácticas: sobre la teoría de la acción. España: Editorial Anagrama.

. (1996). Espíritus del Estado. Génesis y estructura del campo burocrático. Revista Sociedad, 5-30.

. (1990). Sociología y cultura. México: Grijalbo.

. (1985). Qué significa hablar. España: Akal.

- (1982). La representación política: Elementos para una teoría del campo político. Recuperado el 21 de febrero de 2012 de http://davidvelasco.files. wordpress.com/2009/01/la-representacion-politica.pdf

Bourdieu, P. Chamboredon, J. \& Passeron, J. (2003) El oficio de sociólogo: presupuestos epistemológicos (5). España: Siglo XXI Editores.

Bourdieu, P. y Wacquant, L. (1992). Una invitación a la sociología reflexiva. Argentina: Siglo XXI Editores.

Campaña nacional e internacional por los Derechos de los Pueblos (2009). Oriente antioqueño: Imposición violenta de un modelo de desarrollo. Antioquia: Autores.

Carrizo, W. y León, S. (2007). ¿Qué realidad representa la contabilidad? Pecnia, 5, 17-27. Extraído el 21 de agosto de2011 de http://www3.unileon.es/pecvnia/ pecvnia05/05_017_027.pdf

Chua, W. (1986/2009). Desarrollos radicales en el pensamiento contable. En Gómez, M. y Ospina, C. (Eds.) Avances interdisciplinarios para una comprensión crítica de la contabilidad: Textos paradigmáticos de las corrientes heterodoxas (pp. 103-121). Medellín: Escuela de Administración y Contaduría Pública Universidad Nacional de Colombia y Departamento de Ciencias Contables - Universidad de Antioquia.

Corbett, T. Contabilidad del trúput y costeo por actividades: los factores básicos detrás de cada metodología. Extraído 20 de marzo de 2011 de http://www. google.com.co/url?sa=t\&rct=j\&q=contabilidad $\% 20 \mathrm{del} \% 2$ truput $\% 20$ y\%20costeo $\% 20$ por $\% 20$ actividades $\% 3 \mathrm{~A} \% 201$ os $\% 20$ factores $\% 20$ basicos\%20detr\%C3\%A1s\%20de\%20cada\%20metodologia\&source 
$=$ web \&cd=3\&sqi=2\&ved=0CCYQFjAC\&url=ftp $\% 3 \mathrm{~A} \% 2 \mathrm{~F} \% 2$ Fece.buap. $\mathrm{mx} \% 2$ Fpub\%2FDOCUM_EDUCATIVOS_FCE_F_PORRAS\%2FPROCESO S\%2520DE\%2520PENSAMIENTO\%2520y\%2520TOC\%2FINFORMACI\%2 5D3N\%2520RELACIONADA\%2FCONTABILIDAD\%2520DEL\%2520TRUP UT\%2520Y\%2520COSTEO\%2520POR\%2520ACTIVIDADES.doc\&ei=t3Gl Ts3bE8OItwf5iPmkBQ\&usg=AFQjCNELAg3RqHBarozeB5t5PWabkL6zQA Diagnóstico de Salud Municipal - Integración Social (Rionegro-Antioquia). Extraído el 16 de marzo de 2011 de http://salud.rionegro.gov.co/index. php?option=com_content\&view=article\&id=11\&Itemid=18\&limitstart $=1$

Fajardo D. (2000, febrero). Tierra, poder político y reforma agraria y rural. En Cuadernos tierra y justicia, 1. Extraído el 19 de marzo de 2012 de http:// www.kus.uu.se/CF/Cuaderno_01.pdf

Galeano, M. (2004) Estrategias de investigación social cualitativa: el giro de la mirada. Medellín: La Carreta.

Gaviria, C.y Muñoz, J. (2007). Desplazamiento forzado y propiedad de la tierra en Antioquia, 1996-2004. Lecturas de Economía 66, 11-45.

Gil, J. (2009). Retos de la Contabilidad frente a la Globalización: Perspectivas de la teoría y la investigación contable. Cali: Pontificia Universidad Javeriana. . (2003). Conocimiento contable e identidad latinoamericana. Porik An. 07-08 (05), 17-77.

Gómez M. (2009). Los informes contables externos y la legitimidad organizacional con el entorno: estudio de un caso en Colombia. Innovar, 19 (34), 147-166. . (2007). Pensamiento único y contabilidad: La posibilidad de la contabilidad como disciplina moral. Revista Facultad de Ciencias Económicas: Investigación y reflexión. Universidad Militar Nueva Granada, 2 (15), 29-43.

. (2004) Breve introducción al estado del arte de la orientación crítica en la disciplina contable. Revista Contaduría. Universidad de Antioquia 45, 113-132.

Gómez, M. y Ospina, C. (2009) Comentario: Sobre la necesidad de una recreación organizacional y social de los sistemas contables en Colombia. En Gómez, M. y Ospina, C. (Eds.) Avances interdisciplinarios para una comprensión crítica de la contabilidad: Textos paradigmáticos de las corrientes heterodoxas (122125). Medellín: Escuela de Administración y Contaduría Pública - Universidad Nacional de Colombia y Departamento de Ciencias Contables - Universidad de Antioquia. 
Hamilton y O'Hogartaigh (2009). The Third Policeman: 'The true and fair view', language and the habitus of accounting (Traducción propia). Critical Perspectives on Accounting. 20, 910-920.

Lahire, B. (2005). El trabajo sociológico de Pierre Bourdieu: Deudas y críticas. Argentina: Siglo XXI Editores.

Larrinaga G. C. (1999). Perspectivas alternativas de investigación en contabilidad: Una revisión. Revista de contabilidad. 3 (2), 103-131.

Lizcano, M. (2011). Colombia un país desigual, en Portafolio. Extraído el 19 de marzo de 2012 de http://www.portafolio.co/opinion/colombia-un-pais-desigual

Machado, M. (2009). La representación contable del mundo real. Revista Contaduría. Universidad de Antioquia. 54, 191-203.

Mandato Agrario (2003). Extraído el 21 de febrero de 2012 de http://www.kus. uu.se/pdf/publications/mandato_agrario2003.pdf

Marx, C. (1955a). El dieciocho brumario de Luis Bonaparte. En: Obras escogidas de Carlos Marx y Federico Engels (pp. 230-323). Moscú: Editorial Progreso. - (1955b) Manifiesto Comunista. En: Obras escogidas de Carlos Marx y Federico Engels, pp. 230-323. Moscú: Editorial Progreso.

Mattessich, R. (2003). La representación contable y la realidad. La oferta productiva rural en el Oriente Antioqueño. Extraído el 20 de agosto de 2011 de http://www. mgeu.uma.es/CONFERENCIAS/Reality-Malaga-LV.pdf

Mesa de trabajo por los Derechos Humanos y el Desarrollo del Oriente Antioqueño (2006). Informe sobre la situación de los derechos humanos y el derecho internacional humanitario en el Oriente Antioqueño año 2005. El Ágora USB)01 (6), 63-78.

Miller, P. y O'Leary, T. (2009). La contabilidad y la construcción de la persona gobernable. En Gómez, M. y Ospina, C. (Eds.). Avances interdisciplinarios para una comprensión crítica de la contabilidad: Textos paradigmáticos de las corrientes heterodoxas (pp. 175-217). Medellín: Escuela de Administración y Contaduría Pública - Universidad Nacional de Colombia y Departamento de Ciencias Contables - Universidad de Antioquia.

Moncada, J. (2009). Un diagnóstico sobre cadáveres sin identificar (NN) producto del conflicto armado, registrados e inhumados en cementerios del Oriente Antioqueño. El Ágora USB)01(9), 69-83. 
Mondragón, H. (2002). La organización campesina en un ambiente de terror. Extraído el 21 de febrero de 2012 de http://www.kus.uu.se/CF/Oganizacion_ campesina.pdf

Oakes, L; Townley, B \& Cooper, D. (2009). La planeación de negocios como pedagogía: Lenguaje y control en un campo institucional cambiante. En Gómez, M. y Ospina, C. (Eds.). Avances interdisciplinarios para una comprensión crítica de la contabilidad: Textos paradigmáticos de las corrientes heterodoxas (pp. 175-217). Medellín: Escuela de Administración y Contaduría Pública Universidad Nacional de Colombia y Departamento de Ciencias Contables - Universidad de Antioquia.

Padilla, M. (2007). Aproximación al aporte de Pierre Bourdieu a la teoría e investigación sociológica. Marcelo. Revista confluencia, 3 (6), 333-351.

Pérez L. (2011, febrero). Movimientos y resistencias sociales en el Oriente Antioqueño: Nuevos desafíos. En Cuadernos de Sociología UDEA. Extraído el16 de marzo de 2011 de http://cuadernosdesociologiaudea.wordpress. com/tag/oriente-antioqueno/

PLANEO. (2009). Plan estratégico para un pacto social por el desarrollo del Oriente Antioqueño, segunda parte. Extraído el 16 de marzo de 2011 de http://www. google.com.co/url?sa=t\&source $=$ web\&cd $=1 \&$ ved $=0$ CBwQFjAA\&url=http\%3 A\%2F\%2Fwww.orientecomercialdigital.com\%2Fsitio\%2Fdescargar.php\%3Fr \%3D..\%2Fimages\%2Fnoticias\%2F\%26a\%3DPublicacionPlaneo2.pdf\&ei=fO0 9TsuMHofBtgfk9IXBBw\&usg=AFQjCNHRccUjI8WaT_RVIIHmnCMKn3ERjg . (2008). La oferta productiva rural en el Oriente Antioqueño. Extraído el 16 de marzo de 2011 de http://planestrategicodeloriente.blogspot.com/

Powel, W. y Dimaggio, P. (1999). El nuevo institucionalismo en el análisis organizacional. México: Fondo de Cultura Económica- UNAM.

Richardson, A. (2009). La Contabilidad como institución de legitimación. En Gómez, M. y Ospina, C. (Eds.). Avances interdisciplinarios para una comprensión crítica de la contabilidad: Textos paradigmáticos de las corrientes heterodoxas (pp. 79-99). Medellín: Escuela de Administración y Contaduría Pública - Universidad Nacional de Colombia y Departamento de Ciencias Contables - Universidad de Antioquia. 
Rincón, L. y Tabasura, I. (2007). La protesta social agraria en Colombia 1990-2005: génesis del movimiento agrario. En Revista Luna Azul, 24, 42-51. Extraído el 19 de marzo de 2012 de http://lunazul.ucaldas.edu.co/downloads/Revista24_6.pdf

Roberts, J. y Scapens, R. (2009). Sistemas contables y sistemas de rendición de cuentas: comprendiendo las prácticas contables en sus contextos organizacionales. En Gómez, M. y Ospina, C. (Eds.). Avances interdisciplinarios para una comprensión crítica de la contabilidad: Textos paradigmáticos de las corrientes heterodoxas (pp. 103-121). Medellín: Escuela de Administración y Contaduría Pública - Universidad Nacional de Colombia y Departamento de Ciencias Contables - Universidad de Antioquia.

Ronderos, M. (2010). ¿Por qué Colombia no sale del club de los pobres? en Semana.com. Extraído el 21 de febrero de 2012 de http://www.semana. com/nacion/colombia-no-sale-del-club-pobres/136288-3.aspx

Ryan, B.; Scapens. R.\& Theobald, M. (2004). Metodología de la investigación en finanzas y contabilidad. España: Ediciones Deusto.

Sandoval, M. (2002). Pierre Bourdieu y la teoría sobre la dominación masculina. Revista Colombiana de Sociología, 1(7), 55-73.

Semana (2011). Desigualdad extrema. Extraído 16 de marzo de 2011 de http:// www.semana.com/nacion/desigualdad-extrema/153207-3.aspx

Téllez, I. (1992). Pierre Bourdieu: conceptos básicos y construcción socioeducativa: claves para su lectura. Colombia, Bogotá: Universidad Pedagógica Nacional.

Tovillas, P. (2010). Bourdieu: una breve introducción. Buenos Aires: Quadrata.

Vlaemminck, J. (1991). La contabilidad en la antigüedad: de historias y doctrinas de la contabilidad. España: Index.

Zapata, D. (2003). Guerra en el Oriente Antioqueño. En agencia de prensa rural. Extraído el 16 de marzo de 2011 de http://prensarural.org/ruben20031209a. htm

Zuluaga, A. y Giraldo, D. (2011). Pensar sociológicamente el Oriente. En Cuadernos de Sociología Universidad deAntioquia. Extraído el 16 de marzo de 2011 de http://cuadernosdesociologiaudea.wordpress.com/tag/oriente-antioqueno/ 